\title{
Folate receptor-mediated boron-10 containing carbon nanoparticles as potential delivery vehicles for boron neutron capture therapy of nonfunctional pituitary adenomas
}

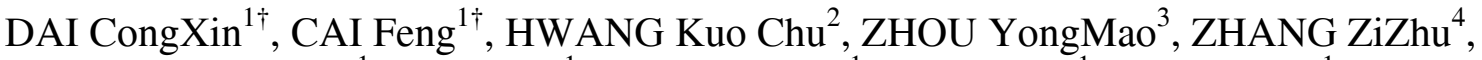 \\ LIU XiaoHai ${ }^{1}$, MA SiHai ${ }^{1}$, YANG YaKun ${ }^{1}$, YAO Yong ${ }^{1}$, FENG Ming ${ }^{1}$, \\ BAO XinJie ${ }^{1}$, LI GuiLin ${ }^{1}$, WEI JunJi ${ }^{1}$, JIAO YongHui ${ }^{1}$, \\ WEI ZhenQing ${ }^{1}$, MA WenBin ${ }^{1} \&$ WANG RenZhi ${ }^{1 *}$ \\ ${ }^{1}$ Department of Neurosurgery, Peking Union Medical College Hospital, Chinese Academy of Medical Sciences \& \\ Peking Union Medical College, Beijing 100730, China; \\ ${ }^{2}$ Department of Chemistry, Tsing Hua University, Hsinchu 300 43, Taiwan, China; \\ ${ }^{3}$ China Zhongyuan Engineering Corporation, China National Nuclear Corporation, Beijing 100191, China; \\ ${ }^{4}$ China Nuclear Industry Beijing 410 Hospital of China Institute of Atomic Energy, Beijing 101213, China
}

Received November 21, 2012; accepted December 10, 2012; published online January 17, 2013

\begin{abstract}
Invasive nonfunctional pituitary adenomas (NFPAs) are difficult to completely resect and often develop tumor recurrence after initial surgery. Currently, no medications are clinically effective in the control of NFPA. Although radiation therapy and radiosurgery are useful to prevent tumor regrowth, they are frequently withheld because of severe complications. Boron neutron capture therapy (BNCT) is a binary radiotherapy that selectively and maximally damages tumor cells without harming the surrounding normal tissue. Folate receptor (FR)-targeted boron-10 containing carbon nanoparticles is a novel boron delivery agent that can be selectively taken up by FR-expressing cells via FR-mediated endocytosis. In this study, FR-targeted boron-10 containing carbon nanoparticles were selectively taken up by NFPAs cells expressing FR but not other types of non-FR expressing pituitary adenomas. After incubation with boron-10 containing carbon nanoparticles and following irradiation with thermal neutrons, the cell viability of NFPAs was significantly decreased, while apoptotic cells were simultaneously increased. However, cells administered the same dose of FR-targeted boron-10 containing carbon nanoparticles without neutron irradiation or received the same neutron irradiation alone did not show significant decrease in cell viability or increase in apoptotic cells. The expression of Bcl-2 was down-regulated and the expression of Bax was up-regulated in NFPAs after treatment with FR-mediated BNCT. In conclusion, FR-targeted boron-10 containing carbon nanoparticles may be an ideal delivery system of boron to NFPAs cells for BNCT. Furthermore, our study also provides a novel insight into therapeutic strategies for invasive NFPA refractory to conventional therapy, while exploring these new applications of BNCT for tumors, especially benign tumors.
\end{abstract}

nonfunctional pituitary adenomas, folate receptor, nanoparticles, boron neutron capture therapy

Citation: Dai C X, Cai F, Hwang K C, et al. Folate receptor-mediated boron-10 containing carbon nanoparticles as potential delivery vehicles for boron neutron capture therapy of nonfunctional pituitary adenomas. Sci China Life Sci, 2013, 56: 163-173, doi: 10.1007/s11427-012-4433-5

Pituitary adenomas (PAs) account for approximately $15 \%$ of intracranial tumors and are the second most common

$\dagger$ Contributed equally to this work

*Corresponding author (email: wangrz@126.com) intracranial neoplasm after gliomas [1]. Nonfunctional pituitary adenomas (NFPAs) are the most common form of PA and account for approximately $30 \%$ of PAs [2]. Because of the lack of clinical symptoms, NFPAs are often diagnosed with variable delay at which point patients suffer from 
compression symptoms (hypopituitarism, headache and visual field defects). Surgery is the first-line treatment for NFPAs, but approximately $40 \%$ of them have invasion of bone, dura, and/or adjacent structures. These invasive NFPAs are difficult to resect completely and the patients often develop tumor recurrence quickly after initial surgery [3]. Thus, further pharmacotherapy is required to control symptoms. However, to date no medical treatment has proven to be clinically effective in the control of NFPAs. Although conventional radiotherapy and stereotactic radiosurgery are useful third-line strategies to prevent tumor regrowth, they are associated with severe complications such as secondary brain neoplasm, optic neuropathy, cerebrovascular accidents, and hypopituitarism, which can seriously impair patients' quality of life or lead to death [4-6]. Therefore, there is an urgent need to identify new therapeutic strategies for invasive NFPAs refractory to standard therapy including repeated surgeries, radiotherapy and alternative medical therapies.

Boron neutron capture therapy (BNCT) is a binary form of radiation therapy that selectively and maximally damages tumor cells without harming the surrounding normal tissue [7]. BNCT is based on nuclear reactions that occur when boron-10 atoms are irradiated by low-energy thermal neutrons to yield alpha particles and recoiling lithium-7 nuclei, which have high lineal energy transfer (LET) values and significant biological effects [8]. The path-lengths of alpha particles and recoiling lithium-7 nuclei are 9 and $5 \mu \mathrm{m}$, respectively, which is approximately the diameter of a single tumor cell. Therefore, the lethality of these nuclei is limited to boron-containing tumor cells, while normal cells survive without exposure to alpha particles and recoiling lithium-7 nuclei [9]. Two fundamental criteria must be met for BNCT: (i) the drug must deliver boron to tumor tissues in concentrations greater than $20-30 \mu \mathrm{g} \mathrm{g}^{-1}$ tissue at the time of irradiation; (ii) there must be an appropriate source of thermal neutrons for BNCT [10].

The major challenge in the development of BNCT is to develop a safe and selective boron delivery agent. Successful boron agents for BNCT are required to accumulate high boron concentrations in tumor cells with high selectivity and with minimal normal tissue toxicity. Currently, sodium borocaptate (BSH) and boronophenylalanine (BPA) are used clinically for patients [11]. However, BSH and BPA have failed to satisfy clinical requirements completely because of their limitations, such as insufficient selectivity, toxicity to the human body, low retention time in tumors and low chemical stability [12].

Folate receptor (FR) is an important therapeutic target for tumor treatment. Folic acid (folate) can bind to FR with high affinity and transport drugs into cells via FR-mediated endocytosis [13]. Previously, FR-targeted boron-10 containing carbon nanoparticles could be selectively taken up by highly FR-expressing HeLa cells and effectively kill the cells upon neutron irradiation [14]. Folate receptor alpha
$(\mathrm{FR} \alpha)$ was shown to be uniquely overexpressed in NFPAs but not in functional pituitary adenomas (PFAs) or normal pituitary glands [15]. Moreover, we previously showed that expression of FR $\alpha$ in NFPAs correlated positively with tumor invasiveness and proliferation [16]. These findings raise the possibility that FR-targeted boron-10 containing carbon nanoparticles may be selectively taken up by NFPA cells for BNCT. In the present study, we sought to expand the application of BNCT for the treatment of NFPAs and determine whether FR-targeted boron-10-containing carbon nanoparticles could be used for the delivery of boron-10 to NFPA cells for BNCT.

\section{Materials and methods}

\subsection{Chemicals and reagents}

FR-targeted boron-10-containing carbon nanoparticles were synthesized by Professor Hwang Kuo Chu (Department of Chemistry, Tsing Hua University, Hsinchu, Taiwan, China) [14]. Folate free RPMI 1640 medium was bought from Invitrogen (Beijing, China). Free folate was purchased from Sigma-Aldrich (Shanghai, China). The cell counting kit (CCK)-8 was supplied by Dojindo Laboratories (Kumamoto, Japan). Annexin V-FITC apoptosis assay kit was supplied by Biosea Biotechnology. The primary antibody for Bax was obtained from Santa Cruz Biotechnology (Santa Cruz, CA, USA), and primary antibody for $\mathrm{Bcl}-2$ was provided by Cell Signaling Technology (Danvers, MA, USA). Mouse anti-FR $\alpha$ antibody (LS-C23683) was obtained from Lifespan BioSciences (Seattle, WA, USA), and the Cy3 affinipure goat anti-mouse IgG secondary antibody (E031610-01) was bought from EarthOx (San Francisco, CA, USA).

\subsection{Neutron resources device}

The source of neutrons was an in-hospital neutron irradiator mark 1 reactor (IHNI-1) (Beijing, China), designed by a member of the Chinese Academy of Engineering, Zhou YongMao and his colleagues [17]. IHNI-1 is exclusively used for boron neutron capture therapy (BNCT) based on a miniature neutron source reactor. The maximum of thermal neutron flux of IHNI-1 for irradiation is up to $1.8 \times 10^{9}$ $\mathrm{n} \mathrm{cm}^{-2} \mathrm{~s}^{-1}$. IHNI-1 is very safe and convenient for both the patients and operators.

\subsection{Primary cell culture}

Nineteen specimens of PAs (mean maximal diameter 32.3 \pm $9.4 \mathrm{~mm}$ ) were obtained from surgical patients, who were hospitalized in the Peking Union Medical College Hospital (PUMCH) between September and November, 2011. All procedures related to tumor tissue handling were approved by the Research Ethics Committee of Peking Union Medical 
College. Informed consent was obtained from every patient before the in vitro study.

Specimens were collected from patients with 10 NFPAs, 3 prolactin (PRL)-secreting PAs, 3 growth hormone $(\mathrm{GH})$ secreting PAs and 3 adrenocorticotropic hormone (ACTH)producing PAs who underwent surgery. To culture primary PA tumor cells, tumor tissues were minced with scissors and digested in Accutase ${ }^{\mathrm{TM}}$ (Invitrogen) containing $1 \mathrm{mg}$ of DNAse at $37^{\circ} \mathrm{C}$ for $1 \mathrm{~h}$. After digestion, cells were suspended, passed through a $40 \mu \mathrm{m}$ cell strainer and cultured in folate-free RPMI 1640 media (Invitrogen) supplemented with $10 \%$ fetal bovine serum (FBS), penicillin $\left(100 \mathrm{U} \mathrm{mL}^{-1}\right)$, streptomycin $\left(100 \mu \mathrm{g} \mathrm{mL}^{-1}\right), \mathrm{B}-27^{\circledR}$ Supplement, N-2 ${ }^{\circledR}$ Supplement, bFGF (20 ng mL ${ }^{-1}$; Peprotech, Suzhou) and EGF (20 ng mL ${ }^{-1}$; Peprotech, Suzhou).

\subsection{Immunofluorescence analysis of FR $\alpha$ expression}

The expression of FR $\alpha$ on the membrane of primary culture PAs cells was determined by fluorescence immunocytochemistry using confocal microscopy. Nineteen PA cells and positive control HeLa cells were planted into glass-bottomed dishes (Nest Biotechnology Corporation, Shanghai) coated with BD Matrigel ${ }^{\mathrm{TM}}$ Basement Membrane Matrix in folate-free RPMI 1640. After 48-h incubation (in an incubator with $80 \%$ humidity and $\mathrm{O}_{2} / \mathrm{CO}_{2}$ at $5 \%$ ) the cells were fixed in $4 \%$ paraformaldehyde for $30 \mathrm{~min}$, and permeabilized with $0.5 \%$ Triton X-100 for 5 min. After incubation with blocking medium (PBS containing 10\% normal horse serum and 2\% BSA) for $30 \mathrm{~min}$, cells were incubated with FR $\alpha$ primary antibody (LS-C23683, Lifespan BioSciences) overnight at $4^{\circ} \mathrm{C}$. After three washes with PBS ( 5 min each), the cells were incubated with the Cy3 affinipure goat anti-mouse IgG (E031610-01, EarthOx) at room temperature for $2 \mathrm{~h}$. Following three washes with PBS, the cell nuclei were stained with 4'6-diamidino-2-phenylindole (DAPI) for $30 \mathrm{~min}$. After three washes with PBS (5 min each), the cells were covered with fluorescence mounting medium. Finally, the cells were visualized under a confocal scanning laser microscope (Zeiss 510; Zeiss, Heidelberg, Germany) and image analysis was performed using the standard system operating software provided with the Zeiss 510 microscope.

\subsection{Uptake of FR-targeted Boron-10 containing carbon nanoparticles by pituitary adenoma cells}

Nineteen cases (10 NFPA with 8 cases overexpressing FR $\alpha$, 3 PRL, $3 \mathrm{GH}$ and 3 ACTH cases) of primary culture PA cells were cultured on glass-bottomed dishes coated with $100 \mu \mathrm{L}$ BD Matrigel ${ }^{\mathrm{TM}}$ Basement Membrane Matrix in folate-free RPMI 1640 for $24 \mathrm{~h}$. FR-targeted boron-10 containing carbon nanoparticles were added to folate-free RPMI 1640 and incubated for $24 \mathrm{~h}$ at $37^{\circ} \mathrm{C}$. Free folate $\left(1 \mathrm{mmol} \mathrm{L} \mathrm{L}^{-1}\right)$ was added to the incubation media of the FR $\alpha$ blocking group to determine the role of FR $\alpha$ binding. The cells were washed three times with cold PBS to remove unbound FR-targeted boron-10 containing carbon nanoparticles after incubation. Then the cell nuclei were stained with DAPI for $30 \mathrm{~min}$. The cells were examined using a confocal scanning laser microscope.

1.6 Cytotoxicity measurements of FR-targeted boron10 containing carbon nanoparticles without neutron irradiation

To measure the cytotoxicity of FR-targeted boron-10 containing carbon nanoparticles, primary culture NFPA cells and GH-secreting PA cells were diluted with folate-free RPMI 1640 medium and seeded in 96-well plates at $1 \times 10^{4}$ cells/well. Then the plate was incubated at $37^{\circ} \mathrm{C}$ for $24 \mathrm{~h}$ in an incubator. Then $20 \mu \mathrm{L}$ of PBS buffer solution containing different amounts of FR-targeted boron-10 containing carbon nanoparticles (ranging from 0.1 to $100 \mu \mathrm{g} \mathrm{mL} \mathrm{m}^{-1}$ ) were added to the wells, whereas $20 \mu \mathrm{L}$ of PBS buffer solution only was added to the control group. Then, the plates were incubated for another $24 \mathrm{~h}$ at $37^{\circ} \mathrm{C}$ in an incubator. CCK-8 $(10 \mu \mathrm{L})$ was added to each well followed by incubation at $37^{\circ} \mathrm{C}$ for $3 \mathrm{~h}$. Finally, the absorbance was measured at a wavelength of 450-630 nm using a Victor-2 plate reader (Perkin Elmer, Waltham, MA, USA). Each experiment was performed three times. Cell viability was calculated as a percentage of the control. Data are the mean \pm SD from a single experiment performed with three duplicates.

\subsection{Intracellular boron concentration measurement}

To measure the boron concentration in PA cells accurately, the primary culture of NFPA cells and GH-secreting PA cells was incubated with $0.1 \mu \mathrm{g} \mathrm{mL}^{-1}$ FR-targeted boron-10 containing carbon nanoparticles in folate-free RPMI 1640 medium. The cells were collected at 2, 4, 8, 16 and $24 \mathrm{~h}$ after the addition of FR-targeted boron-10 containing carbon nanoparticles. The free FR-targeted boron-10 containing carbon nanoparticles in the medium were removed by centrifugation at $1000 \times g$ for $5 \mathrm{~min}$ and re-suspended in PBS. This procedure was repeated three times. The cells were collected and the boron concentration was determined by inductively coupled plasma-atomic emission spectrum (ICP-AES) according to a previously described method [18].

\subsection{Thermal neutron irradiation experiments}

The primary culture NFPA cells were planted in the center of 16 wells of a 96-well plate at a density of $1 \times 10^{4}$ cells/ well, following an addition of $20 \mu \mathrm{L}$ of a PBS buffer solution containing $0.05,0.1$ or $0.2 \mu \mathrm{g}$ of FR-targeted boron-10 
containing carbon nanoparticles to the treatment groups, and $20 \mu \mathrm{L}$ of PBS only to the control group. After 24-h incubation the free FR-targeted boron-10 containing carbon nanoparticles were removed from the medium by centrifugation and wash with PBS for three times. Then the cells were returned to a 96-well plate and irradiated by a thermal neutron beam from the nuclear reactor. The control for each group received the same neutron dose but without incubation with carbon nanoparticles. After irradiation at a neutron flux of $1.8 \times 10^{9} \mathrm{n} \mathrm{cm}^{-2} \mathrm{~s}^{-1}$ for $10 \mathrm{~min}$, the 96 -well plates were further incubated at $37^{\circ} \mathrm{C}$ for 24 and $48 \mathrm{~h}$ to determine cell viability using CCK-8.

\subsection{Annexin V/PI analysis}

At $48 \mathrm{~h}$ after NFPA cell irradiation with thermal neutrons, the Annexin V/PI assays were performed according to the manufacturer's protocol (Biosea, China). Briefly, the NFPA cells were washed twice with PBS and resuspended with $200 \mu \mathrm{L}$ binding buffer. $10 \mu \mathrm{L}$ of Annexin-V-FITC was added to the cells, followed by $30 \mathrm{~min}$ incubation at room temperature in the dark. After incubation, cells were counterstained with $5 \mu \mathrm{L}$ PI (Sigma). The percentage of apoptotic cells was determined using a FACS flow cytometer. Each experiment was performed three times. Data are the mean \pm SD from a single experiment with three duplicates.

\subsection{Western blotting}

To investigate the mechanisms involved in BNCT-induced cell death of NFPA cells, the expressions of Bax and Bcl-2 were performed at $48 \mathrm{~h}$ after irradiation with thermal neutrons. Briefly, cell lysates were separated on a $10 \%$ polyacrylamide gel, electrophoretically transferred onto a PVDF membrane (PALL Corp., East Hills, NY, USA) and probed by standard techniques with primary antibodies raised against Bax and Bcl-2. All antibodies were used at a 1:1000 dilution. HRP-conjugated goat anti-rabbit IgG (Cell Signaling Technology) were used as secondary antibodies for rabbit anti-Bax (Santa Cruz Biotechnology) and rabbit antiBcl-2 (Cell Signaling Technology) primary antibodies. Horse anti-human IgG (Cell Signaling Technology) was used as a secondary antibody for the human anti- $\beta$-actin primary antibody (Santa Cruz Biotechnology).

\subsection{Statistical analysis}

The data were expressed as the mean $\pm \mathrm{SD}$, with $P<0.05$ being considered statistically significant. The differences among groups were tested by one-way ANOVA, followed by Dunnett's multiple range test. The differences between two groups were evaluated by the unpaired Student's $t$-test. All statistical analyses were performed using SPSS.17.0 statistical software.

\section{Results}

\subsection{The expression of FR $\alpha$ in PAs}

Before exploring whether FR-targeted boron-10 containing carbon nanoparticles could be taken up by NFPA cells for BNCT, the expression and location of FR $\alpha$ in 19 cases of PA was analyzed by immunofluorescence. As shown in Figure 1, NFPA cells exhibited strong membrane staining for FR $\alpha$, similar to the positive control HeLa cells. In contrast, no membrane staining was observed in the FPAs. However, not all NFPA cells showed positive staining of membrane FR $\alpha$. In the present study, 8 of 10 NFPAs showed significant positive staining of $\mathrm{FR} \alpha$, consistent with our previous study [16].

\subsection{Uptake of FR $\alpha$-targeted boron-10 containing car- bon nanoparticles by $\mathrm{PA}$ cells}

The uptake of FR-targeted boron-10 containing carbon nanoparticles by PA cells was analyzed by fluorescence microscopy. Carbon nanoparticles were surface modified with folate moieties, which can induce green fluorescence under a FITC filter. As shown in Figure 2, FR-targeted boron-10 containing carbon nanoparticles were more efficiently taken up by NFPA cells expressing FR $\alpha$ compared to FPAs not expressing FR $\alpha$. FR-mediated uptake could be blocked by $1 \mathrm{mmol} \mathrm{L}^{-1}$ free folic acid. Taken together, our data show that FR-targeted boron-10 containing carbon nanoparticles could effectively be taken up by NFPA cells through FR $\alpha$ mediated endocytosis.

\subsection{Cytotoxicity of FR-targeted boron-10 containing carbon nanoparticles}

To investigate the cytotoxicity of FR-targeted boron-10 containing carbon nanoparticles, we performed CCK-8 assay of PA cells after incubation with various concentrations of FR-targeted boron-10 containing carbon nanoparticles. FR-targeted boron-10 containing carbon nanoparticles reduced the viability of NFPAs in a concentration-dependent manner after $24 \mathrm{~h}$ incubation (Figure 3A). Although viability of GH-secreting adenoma cells also was reduced in a concentration dependent manner, the cell viability was much higher than for NFPAs after incubation with the same concentration of FR-targeted drugs. The above results were similar to the positive control (HeLa cell line) and negative control (non-FR $\alpha$-expressing mouse gonadotroph adenoma cell line, $\alpha \mathrm{T} 3-1$ ), respectively (Figure 3B).

\subsection{Time-course of boron concentration in PAs}

To investigate the time-course of boron accumulation, boron concentration in PAs was evaluated by ICP-AES for 


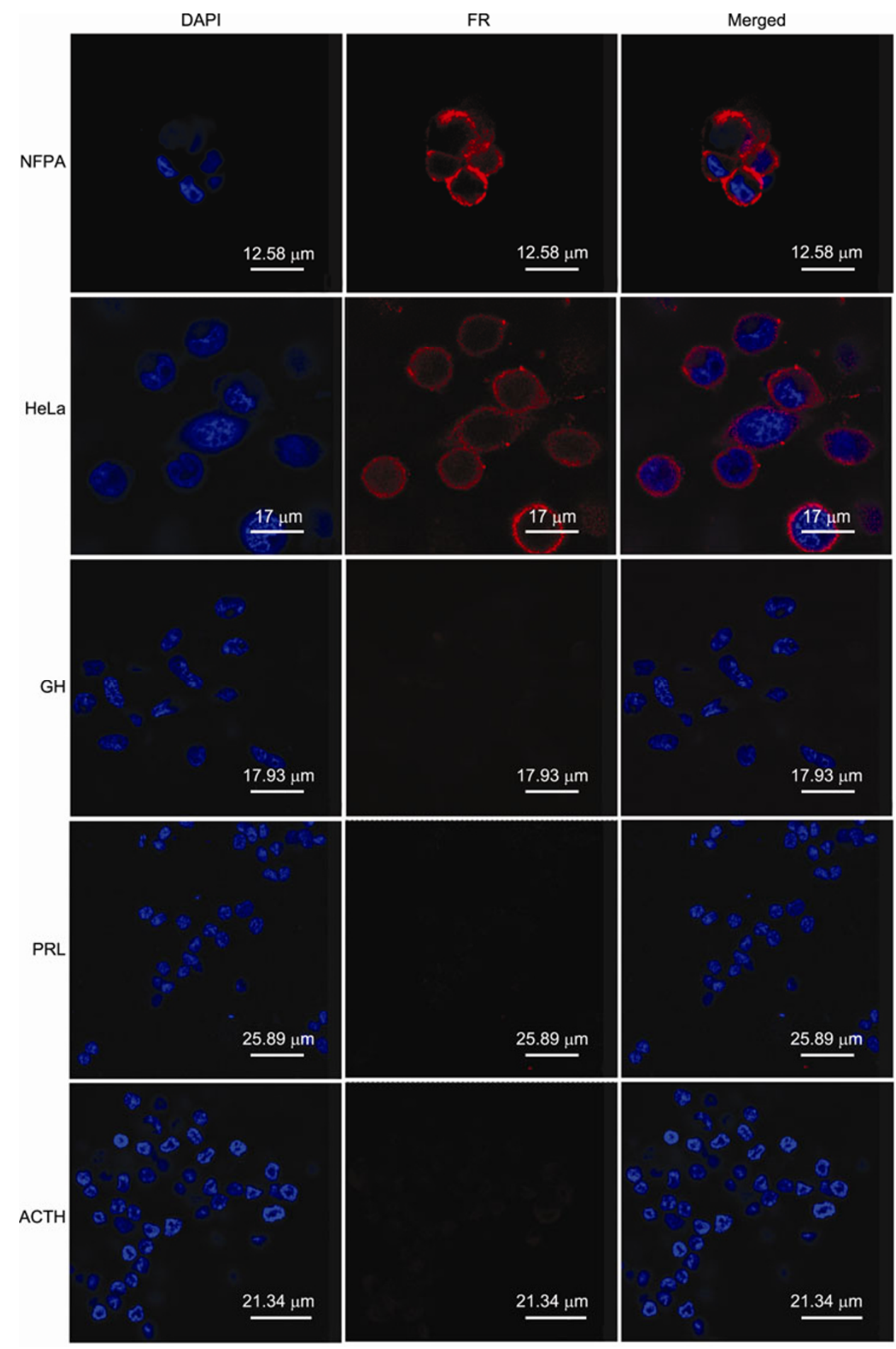

Figure 1 Expression and location of FR $\alpha$ in PAs and HeLa cells. Strong expression of FR $\alpha$ was detected on the cellular membrane of NFPAs and positive control HeLa cells. FR $\alpha$ was not detected on the cellular membrane of GH adenoma cells, PRL adenoma cells and ACTH adenoma cells.

each post-administration time point. Boron accumulation in the NFPA tumor cells increased in a time dependent manner, and the boron concentration reached a maximum value $\left(246.8 \mu \mathrm{g} \mathrm{g}^{-1}\right)$ after $24-\mathrm{h}$ incubation with FR-targeted boron-10 containing carbon nanoparticles (Figure 4A). In contrast, GH-secreting PAs did not show significant increases in boron concentration in a time dependent manner, and the boron concentrations at the same time points were much lower than for NFPA tumor cells. Similar results were observed in the positive control (HeLa cell line) and the negative control ( $\alpha \mathrm{T} 3-1$ cell line) (Figure 4B). The boron concentration in HeLa cells was much higher than in $\alpha \mathrm{T} 3-1$ 


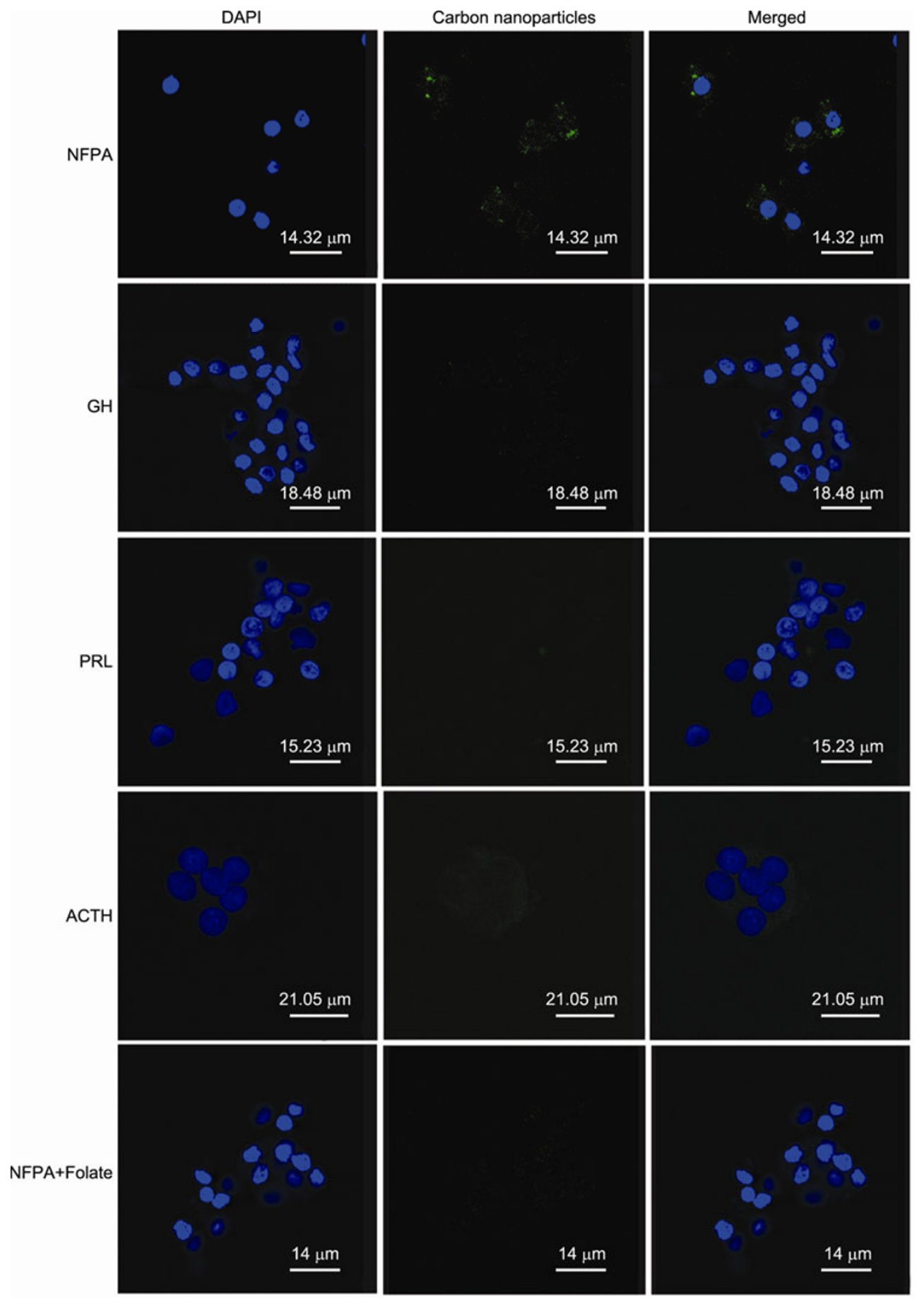

Figure 2 Uptake of FR-targeted boron-10 containing carbon nanoparticles by PAs. PAs were incubated with FR-targeted boron-10 containing carbon nanoparticles at a dose of $0.1 \mathrm{mg} \mathrm{mL}{ }^{-1}$ or FR-targeted boron-10 containing carbon nanoparticles plus $1 \mathrm{mmol} \mathrm{L}^{-1}$ free folic acid for $24 \mathrm{~h}$. Green fluorescence represents the folate moieties on FR-targeted boron-10 containing carbon nanoparticles under a FITC filter. FR-targeted boron-10 containing carbon nanoparticles were taken up by NFPAs with FR $\alpha$ expression. The FR-targeted boron-10 containing carbon nanoparticles were not taken up by GH adenoma cells, PRL adenoma cells or ACTH adenoma cells. The cellular uptake of FR $\alpha$-targeted boron-10 containing carbon nanoparticles could be blocked by addition of $1 \mathrm{mmol} \mathrm{L}{ }^{-1}$ free folate.

cells at the same time after the addition of FR-targeted boron-10 containing nanoparticles (Figure 4B). However, the boron concentration in NFPAs was lower than in HeLa cells, indicating that the uptake ability of FR-targeted boron-10 containing carbon nanoparticles in HeLa cells was more efficient than for NFPAs. 

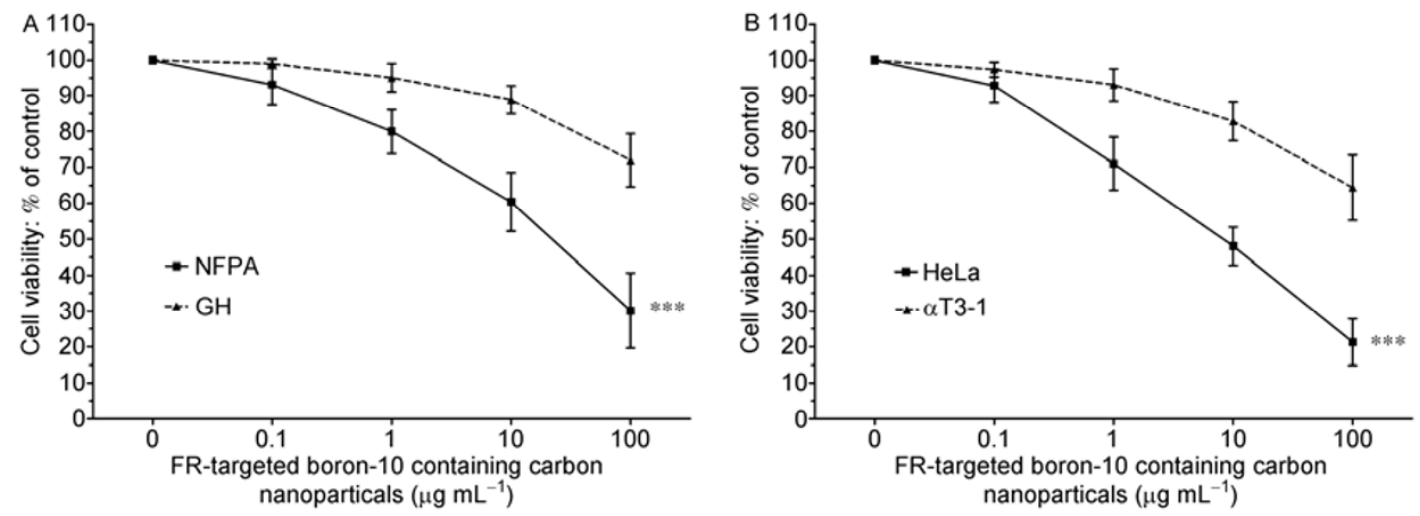

Figure 3 Cytotoxicity of FR-targeted boron-10 containing carbon nanoparticles of PA cell proliferation. NFPA cells expressing FR $\alpha$ or non-FR $\alpha$ expressing GH adenoma cells (A) and positive control (HeLa) and negative control ( $\alpha$ T3-1 cells) (B) were incubated with various doses of FR-targeted boron-10 containing carbon nanoparticles for $24 \mathrm{~h}$. The inhibitory rate of the treatment group was expressed as the $\%$ of control values. Data represent the mean $\pm \mathrm{SD}$ of triplicate experiments. $* * *, P<0.001$ compared with control.
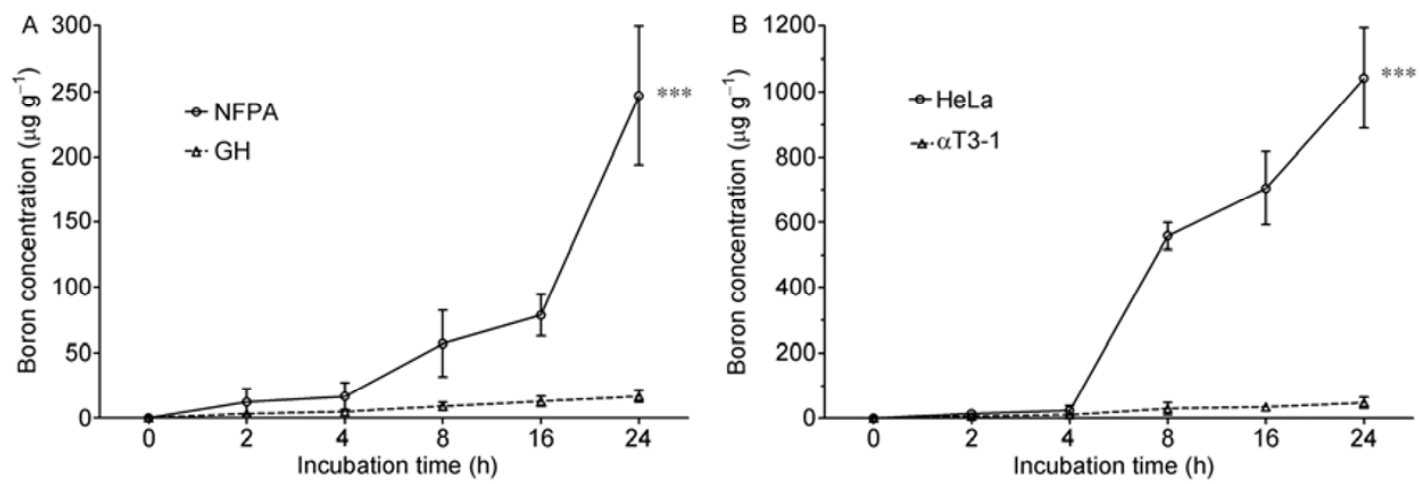

Figure 4 Time course of boron accumulation in tumor cells. NFPA cells expressing FR $\alpha$ or non-FR $\alpha$-expressing GH adenoma cells (A) and positive control (HeLa) and negative control ( $\alpha$ T3-1 cells) (B) were incubated with $0.1 \mu \mathrm{g} \mathrm{mL}^{-1}$ of FR-targeted boron-10 containing carbon nanoparticles for $2,4,8,16$ and $24 \mathrm{~h}$. Boron concentrations in tumors cells were evaluated by ICP-AES. Data represent the mean \pm SD of triplicate experiments. $* * *, P<0.001$.

\subsection{The neutron capture therapeutic (NCT) effects of FR-targeted boron-10 containing carbon nanoparticles on cell viability of NFPAs}

To examine whether FR-targeted boron-10 containing carbon nanoparticles have neutron capture therapeutic (NCT) effects on NFPAs, in vitro cellular experiments were conducted. The cell viability of NFPAs was decreased in a dose- and time-dependent manner after irradiation at a thermal neutron flux of $1.8 \times 10^{9} \mathrm{n} \mathrm{cm}^{-2} \mathrm{~s}^{-1}$. However, cells fed with the same dose of carbon nanoparticles without neutron irradiation or received same neuron irradiation without incubation with FR-targeted boron-10 containing carbon nanoparticles did not show a significant decrease in cell viability (Figure 5A). The similar results also were observed in the Hela (Figure 5B).

2.6 The neutron capture therapeutic (NCT) effects of FR-targeted boron-10 containing carbon nanoparticles on apoptosis of NFPAs cells

To determine the effect of BNCT on apoptosis of NFPA cells, we performed an Annexin V-FITC apoptosis assay. Incubation with FR-targeted boron-10 containing carbon nanoparticles or neutron irradiation alone did not induce significant NFPA cell apoptosis compared with controls (without incubation with FR-targeted boron-10 containing carbon nanoparticles or neutron irradiation) (Figure 6A). Strikingly, the neutron irradiation induced apoptosis of NFPA cells incubated with FR-targeted boron-10 containing carbon nanoparticles increased by up to $28.6 \%$ (Figure 6B). Similar results were obtained in HeLa cells (Figure 6C and D). Taken together, FR-mediated BNCT significantly induced apoptosis of NFPAs cells.

\subsection{The effect of BNCT on Bcl-2 and Bax expression}

To explore the molecular mechanisms of BNCT-induced apoptosis in NFPAs, the levels of Bcl-2, an inner mitochondrial membrane protein that inhibits apoptosis, and Bcl-2associated $\mathrm{X}$ (Bax), a protein that promotes apoptosis by competing with Bcl-2 [19], were evaluated by Western blot. Irradiation with thermal neutrons did not alter the expression of Bcl-2 or Bax in NFPAs in the absence of incubation 

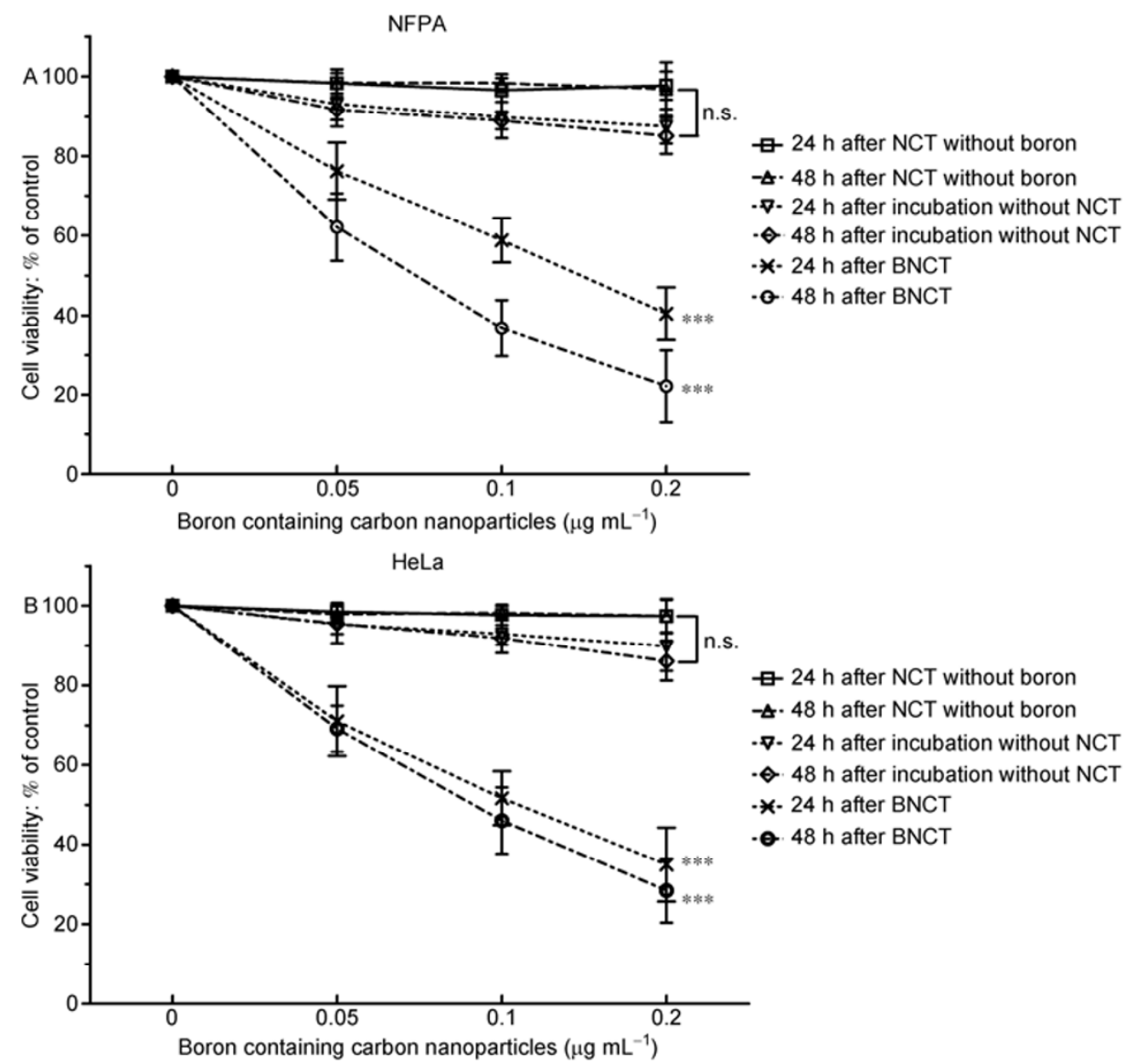

Figure 5 Neutron capture therapeutic (NCT) effects of FR-targeted boron-10 containing carbon nanoparticles on tumors cell viability. After 24 h incubation with or without $0.1 \mathrm{mg} \mathrm{mL}{ }^{-1}$ of FR-targeted boron-10 containing carbon nanoparticles, NFPA cells expressing FR $\alpha$ or non-FR $\alpha$-expressing GH adenoma cells (A) and positive control (HeLa) and negative control ( $\alpha$ T3-1 cells) (B) were irradiated with a thermal neutron flux of $1.8 \times 10^{9} \mathrm{n} \mathrm{cm}^{-2} \mathrm{~s}^{-1}$. Then, cell viabilities were measured at 24 and $48 \mathrm{~h}$ after neutron irradiation. The cells in control group were not incubated with FR-targeted boron-10 containing carbon nanoparticles or irradiated with thermal neuron. (n.s., non significant; ***, $P<0.001$ compared with control.

with FR-targeted boron-10 containing carbon nanoparticles (Figure 7A). However, after treatment with BNCT, the expression of Bcl-2 was markedly down-regulated, while Bax expression was simultaneously up-regulated. Densitometric analysis revealed a marked increase in the Bax/Bcl-2 expression ratio following treatment of $\mathrm{BNCT}$, compared to controls and treatment with thermal neutron irradiation only $(P<0.01)$ (Figure 7B). Taken together, these results indicate that the mechanisms of BNCT-induced apoptosis may partly involve the regulation of $\mathrm{Bcl}-2$ and Bax expression.

\section{Discussion}

In the present study, we demonstrated that FR-targeted boron-10 containing carbon nanoparticles were selectively taken up by primary cultures of NFPAs via FR-mediated endocytosis. Furthermore, FR-mediated BNCT significantly decreased cell viability and increased apoptosis of NFPA cells.

The study of BNCT has progressed in a variety of ma- lignancies over recent decades [7]. In the clinic, BNCT is used to treat patients with high-grade gliomas, melanomas, liver metastasis of colon adenocarcinomas, malignant melanomas, recurrent tumors of head and neck cancer, multiple liver tumors and oral cancer [20-25]. To the best of our knowledge, the effect of BNCT on PAs has not been tested yet, probably because PAs are benign tumors and general boron compounds have relatively low biologically weighted concentrations in PA tumor cells. However, aggressive PAs are frequently invasive of the surrounding anatomical structures and exhibit rapid growth. They are notoriously difficult to manage, are associated with a poor prognosis and are generally refractory to standard therapy. Therefore, the therapeutic options are limited [26]. For these reasons, we focused on the promising therapeutic effects of BNCT for aggressive pituitary tumors. Strikingly, in the present study, the FR-targeted boron-10 containing carbon nanoparticles could selectively transport boron-10 to FR-expressing NFPAs but not FPAs, which fulfilled the basic requirements for BNCT. The BNCT experiments in this study further demonstrated that FR-mediated BNCT is an effective 

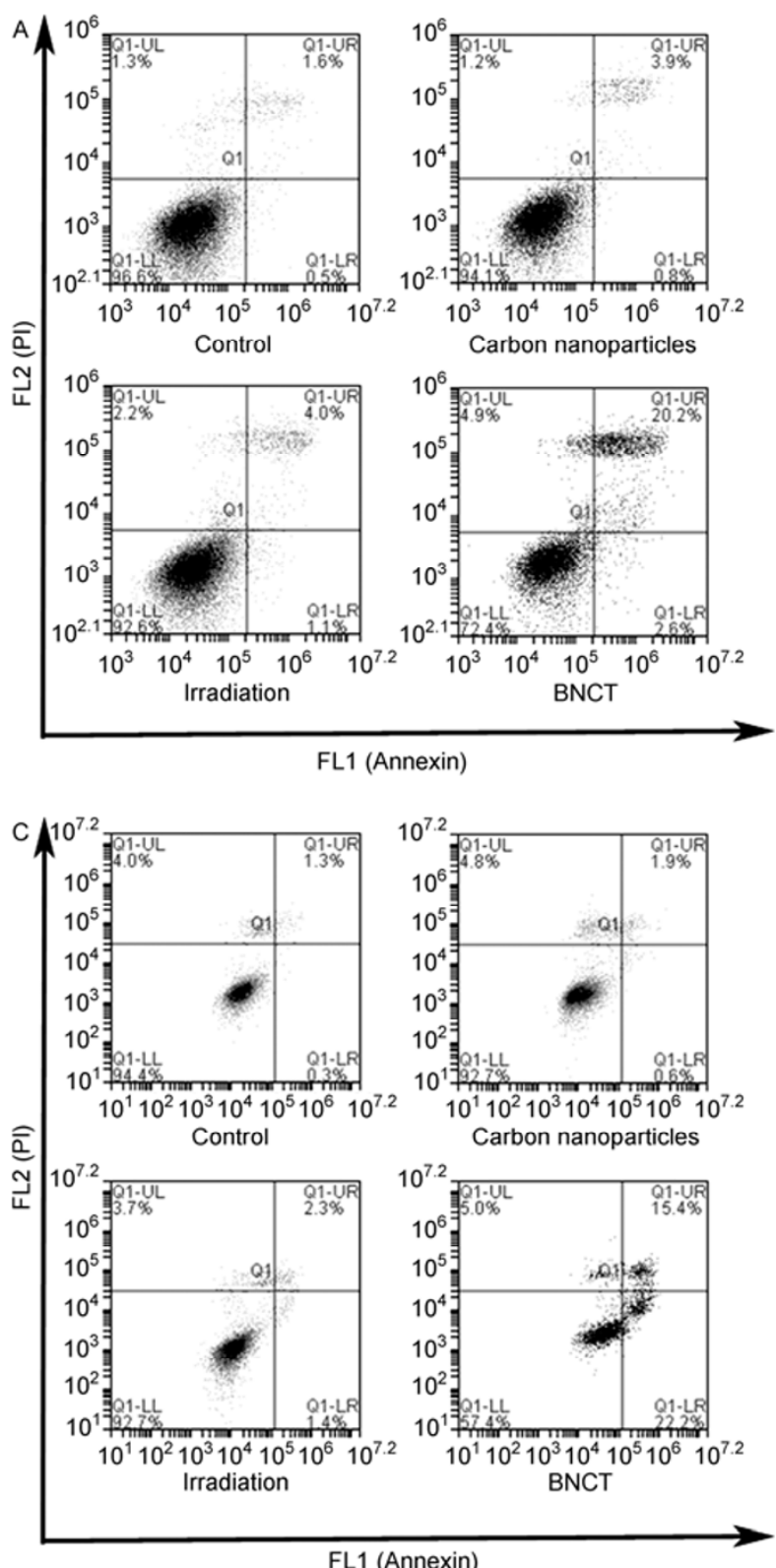

Figure 6 Neutron capture therapeutic (NCT) effects of FR-targeted boron-10 containing carbon nanoparticles on apoptosis of tumors cells. Annexin V-FITC apoptosis assay was performed to detected cell apoptosis of NFPA cells (A and B) and HeLa cells (C and D) at $48 \mathrm{~h}$ after neutron irradiation. Data represent the mean $\pm \mathrm{SD}$ of triplicate experiments. $* * *, P<0.001$ compared with control.

therapeutic treatment for NFPAs without causing excessive radiation damage to the non-FR-expressing $\mathrm{GH}$ secreting adenomas, which is regarded as normal tissue. Taken together, our data showed that FR-mediated BNCT specifically killed primary culture FR-expressing NFPAs.

One of the major challenges in BNCT is the development of ideal boron compounds that are selectively taken up by tumor cells. One previous study demonstrated that FR-targeted boron-10 containing carbon nanoparticles were specifically taken up by HeLa cells, an FR expressing cell line [14]. Other previous studies have also reported that FR $\alpha$ was uniquely overexpressed in NFPAs but was not
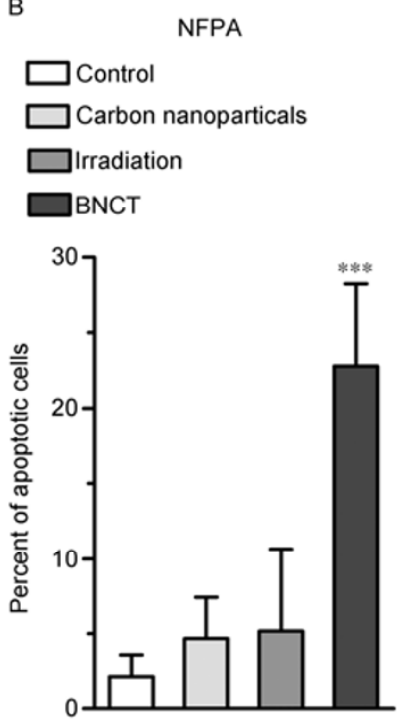

D

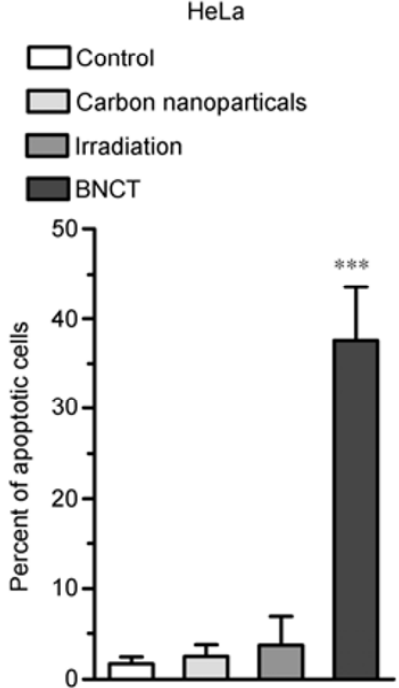

expressed by FPAs or normal pituitary glands cells [15,27]. It is worthwhile to determine whether a FR $\alpha$-targeted boron agent could be used in BNCT for NFPAs, especially invasive NFPAs that are refractory to standard therapy. In the present study, we demonstrated that FR-targeted boron-10 containing carbon nanoparticles could be taken up by FR $\alpha$-positive NFPAs more efficiently than non-FR $\alpha$ expressing FPAs. Furthermore, the FR-mediated uptake of carbon nanoparticles could be inhibited by folic acid, suggesting FR-mediated internalization may be involved in the selective delivery of boron-10 containing carbon nanoparticles to NFPAs. 


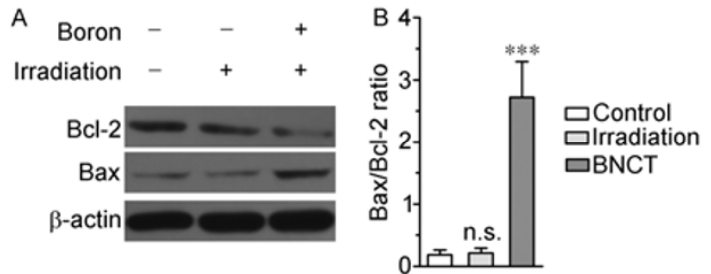

Figure 7 The expression of Bcl-2 and Bax proteins in NFPA cells after neutron irradiation. A, To evaluate the effect of FR-mediated BNCT on apoptosis-related proteins, Western blot analysis of Bcl-2 and Bax expression was performed $48 \mathrm{~h}$ after neutron irradiation. The representative blots of three independent experiments are shown. $\beta$-actin was used as a loading control. B, Densitometric analysis of Bax/Bcl-2 expression ratio of the Western blots. The data are expressed as the mean \pm SD from three independent experiments which were analyzed using one-way ANOVA. ***, $P<0.001$ compared with control.

Our results are consistent with previous reports showing that FR-targeted boron compounds could be selectively taken up by FR-expressing tumor cells [28-31]. In the present study, carbon nanoparticles were surface modified with folate moieties, and therefore could target FR-expressing NFPA cells via a FR-mediated endocytosis process. The folate moieties could generate green fluorescence under the FITC filter, and internalization of carbon nanoparticles could be determined by confocal laser scanning microscopy. The results in this study demonstrate that carbon nanoparticles enter the cytoplasm of FR-expressing NFPA cells but not non-FPA expressing cells, indicating that FR-targeted carbon nanoparticles are an ideal delivery agent of boron for BNCT. Furthermore, we determined the concentration of boron in NFPA cells by ICP-AES was up to $246 \mu \mathrm{g} \mathrm{g}^{-1} 24 \mathrm{~h}$ after incubation with the FR-targeted boron agent. This was approximately 15-fold higher than for GH-secreting adenoma cells. The boron concentration was higher than the standard therapeutic dose of $20-30 \mu \mathrm{g} \mathrm{g}^{-1}$ after $8 \mathrm{~h}$ incubation with FR-targeted carbon nanoparticles. The results demonstrated that FR-mediated boron-10 containing carbon nanoparticles are probably more efficacious for NFPA than first generation and second generation boron delivery agents (such as BPA and BSH) owing to its high selectivity and low toxicity to normal cells.

More importantly, the cell viability of NFPAs administered FR-targeted boron-10 containing carbon nanoparticles decreased and apoptotic cells increased after irradiation with the thermal neutron beam. BNCT may induce glioma cell apoptosis via activation of Bax and downregulation of Bcl-2 [32]. Consistent with a previous study, we observed that neutron irradiation induced the apoptosis of NFPA cells incubated with carbon nanoparticles up to $28.6 \%$, compared to controls $(2.1 \%$, without incubation of carbon nanoparticles or neutron irradiation). Treatment with neutron irradiation alone or incubation with carbon nanoparticles alone did not induce apoptosis of NFPAs, indicating that apoptosis in NFPAs was induced by nuclear reactions occurring in boron-10 irradiated with thermal neutrons. Apoptosis, an ac- tive process of cellular self-destruction, plays an important role in radiation-induced cell death [33]. Bcl-2 is an integral mitochondrial membrane protein that can prevent the initiation of the cell apoptotic program [34]. Bax is an apoptosis-inducing protein that participates in cell death, which is counterbalanced by Bcl-2 [35]. The interactions of Bcl-2 and Bax regulate apoptosis in cells [36]. When apoptosis-inducing protein Bax is present in excess, cells execute a death command; however, when anti-apoptosis protein Bcl-2 dominates, the program is blocked and cells survive [37]. Consistent with the increase in apoptotic cell death, FR-mediated BNCT increased the ratio of Bax/Bcl-2 in NFPA cells after $48 \mathrm{~h}$ of thermal neutron irradiation. Taken together, FR-mediated BNCT may induce apoptosis in NFPAs via regulating Bax/Bcl-2 expression.

Although NFPAs were effectively suppressed by FRmediated BNCT in vitro, no in vivo study was performed due to the scarcity of animal models of NFPA. It remains to be investigated whether the development of a useful animal model truly representing human NFPA is possible and to evaluate the effect of FR-mediated BNCT in this system.

In conclusion, we present evidence that FR-targeted boron-10 containing carbon nanoparticles may be an ideal delivery agent of boron to NFPAs for BNCT. FR-mediated BNCT could decrease cell viability and significantly increase apoptosis in NFPAs in vitro. Furthermore, our study also provides a novel insight into therapeutic strategies for invasive NFPA refractory to conventional therapy, while exploring these new applications of BNCT on tumors, especially benign tumors.

$\begin{array}{ll}\text { Abbreviations } & \\ \text { PAs } & \text { pituitary adenomas } \\ \text { NFPAs } & \text { nonfunctional pituitary adenomas } \\ \text { FPAs } & \text { functional pituitary adenomas } \\ \text { ACTH } & \text { adrenocorticotropic hormone } \\ \text { PRL } & \text { prolactin } \\ \text { GH } & \text { growth hormone } \\ \text { FR } \alpha & \text { folate receptor alpha } \\ \text { CCK-8 } & \text { cell counting kit-8 } \\ \text { BNCT } & \text { boron neutron capture therapy } \\ \text { BSH } & \text { sodium borocaptate } \\ \text { BPA } & \text { boronophenylalanine } \\ \text { IHNI-1 } & \text { irradiator mark 1 reactor } \\ \text { ICP-AES } & \text { inductively coupled plasma-atomic } \\ & \text { emission spectrum }\end{array}$

The authors thank Dr. P. L. Mellon for providing the $\alpha$ T3-1 cell line. This work was supported by the National Natural Science Foundation of China (81072084).

1 Asa S L, Ezzat S. The pathogenesis of pituitary tumours. Nat Rev Cancer, 2002, 2: 836-849

2 Asa S L, Kovacs K. Clinically non-functioning human pituitary ade- 
nomas. Can J Neurol Sci, 1992, 19: 228-235

3 Chang E F, Zada G, Kim S, et al. Long-term recurrence and mortality after surgery and adjuvant radiotherapy for nonfunctional pituitary adenomas. J Neurosurg, 2008, 108: 736-745

4 Losa M, Picozzi P, Motta M, et al. The role of radiation therapy in the management of non-functioning pituitary adenomas. J Endocrinol Invest, 2011, 34: 623-629

5 Pollock B E, Cochran J, Natt N, et al. Gamma knife radiosurgery for patients with nonfunctioning pituitary adenomas: results from a 15-year experience. Int J Radiat Oncol Biol Phys, 2008, 70: 13251329

6 Feigl G C, Pistracher K, Berghold A, et al. Pituitary insufficiency as a side effect after radiosurgery for pituitary adenomas: the role of the hypothalamus. J Neurosurg, 2010, 113(Suppl): 153-159

7 Barth R F. Boron neutron capture therapy at the crossroads: challenges and opportunities. Appl Radiat Isot, 2009, 67: S3-S6

8 Pisarev M A, Dagrosa M A, Juvenal G J. Boron neutron capture therapy in cancer: past, present and future. Arq Bras Endocrinol Metabol, 2007, 51: 852-856

9 Barth R F, Coderre J A, Vicente M G, et al. Boron neutron capture therapy of cancer: current status and future prospects. Clin Cancer Res, 2005, 11: 3987-4002

10 Barth R F, Soloway A H, Fairchild R G, et al. Boron neutron capture therapy for cancer. Realities and prospects. Cancer, 1992, 70: 29953007

11 Barth R F, Yang W, Rotaru J H, et al. Boron neutron capture therapy of brain tumors: enhanced survival and cure following blood-brain barrier disruption and intracarotid injection of sodium borocaptate and boronophenylalanine. Int J Radiat Oncol Biol Phys, 2000, 47: 209-218

12 Panov V, Salomon Y, Kabalka G W, et al. Uptake and washout of borocaptate sodium and borono-phenylalanine in cultured melanoma cells: a multi-nuclear NMR study. Radiat Res, 2000, 154: 104-112

13 Sudimack J, Lee R J. Targeted drug delivery via the folate receptor. Adv Drug Deliv Rev, 2000, 41: 147-162

14 Hwang K C, Lai P D, Chiang C S, et al. Neutron capture nucleicontaining carbon nanoparticles for destruction of cancer cells. Biomaterials, 2010, 31: 8419-8425

15 Evans C O, Reddy P, Brat D J, et al. Differential expression of folate receptor in pituitary adenomas. Cancer Res, 2003, 63: 4218-4224

16 Liu X, Ma S, Yao Y, et al. Differential expression of folate receptor alpha in pituitary adenomas and its relationship to tumor behavior. Neurosurgery, 2012, 70: 1274-1280

17 Ke G, Sun Z, Shen F, et al. The study of physics and thermal characteristics for in-hospital neutron irradiator (IHNI). Appl Radiat Isot, 2009, 67: S234-S237

18 Linko S, Revitzer H, Zilliacus R, et al. Boron detection from blood samples by ICP-AES and ICP-MS during boron neutron capture therapy. Scand J Clin Lab Invest, 2008, 68: 696-702

19 Zhang L, Xing D, Chen M. Bim(L) displacing Bcl-x(L) promotes Bax translocation during TNFalpha-induced apoptosis. Apoptosis, 2008, 13: 950-958

20 Kawabata S, Miyatake S, Nonoguchi N, et al. Survival benefit from boron neutron capture therapy for the newly diagnosed glioblastoma patients. Appl Radiat Isot, 2009, 67: S15-S18

21 Santa C G, Gonzalez S J, Bertotti J, et al. First application of dynamic infrared imaging in boron neutron capture therapy for cutaneous malignant melanoma. Med Phys, 2009, 36: 4519-4529

22 Aihara T, Hiratsuka J, Morita N, et al. First clinical case of boron neutron capture therapy for head and neck malignancies using 18F-BPA PET. Head Neck, 2006, 28: 850-855

23 Kato I, Fujita Y, Maruhashi A, et al. Effectiveness of boron neutron capture therapy for recurrent head and neck malignancies. Appl Radiat Isot, 2009, 67: S37-S42

24 Suzuki M, Sakurai Y, Masunaga S, et al. Dosimetric study of boron neutron capture therapy with borocaptate sodium (BSH)/lipiodol emulsion (BSH/lipiodol-BNCT) for treatment of multiple liver tumors. Int J Radiat Oncol Biol Phys, 2004, 58: 892-896

25 Kimura Y, Ariyoshi Y, Shimahara M, et al. Boron neutron capture therapy for recurrent oral cancer and metastasis of cervical lymph node. Appl Radiat Isot, 2009, 67: S47-S49

26 Colao A, Grasso L F, Pivonello R, et al. Therapy of aggressive pituitary tumors. Expert Opin Pharmacother, 2011, 12: 1561-1570

27 Evans C O, Young A N, Brown M R, et al. Novel patterns of gene expression in pituitary adenomas identified by complementary deoxyribonucleic acid microarrays and quantitative reverse transcriptionpolymerase chain reaction. J Clin Endocrinol Metab, 2001, 86: 30973107

28 Thirumamagal B T, Zhao X B, Bandyopadhyaya A K, et al. Receptor-targeted liposomal delivery of boron-containing cholesterol mimics for boron neutron capture therapy (BNCT). Bioconjug Chem, 2006, 17: 1141-1150

29 Stephenson S M, Yang W, Stevens P J, et al. Folate receptor-targeted liposomes as possible delivery vehicles for boron neutron capture therapy. Anticancer Res, 2003, 23: 3341-3345

30 Shukla S, Wu G, Chatterjee M, et al. Synthesis and biological evaluation of folate receptor-targeted boronated PAMAM dendrimers as potential agents for neutron capture therapy. Bioconjug Chem, 2003, 14: $158-167$

31 Sudimack J J, Adams D, Rotaru J, et al. Folate receptor-mediated liposomal delivery of a lipophilic boron agent to tumor cells in vitro for neutron capture therapy. Pharm Res, 2002, 19: 1502-1508

32 Wang $\mathrm{P}$, Zhen $\mathrm{H}$, Jiang X, et al. Boron neutron capture therapy induces apoptosis of glioma cells through Bcl-2/Bax. BMC Cancer, 2010, 10: 661

33 Yanagihara K, Nii M, Numoto $\mathrm{M}$, et al. Radiation-induced apoptotic cell death in human gastric epithelial tumour cells; correlation between mitotic death and apoptosis. Int J Radiat Biol, 1995, 67: 677-685

34 Yang J, Liu X, Bhalla K, et al. Prevention of apoptosis by Bcl-2: release of cytochrome c from mitochondria blocked. Science, 1997, 275: 1129-1132

35 Mahajan N P, Linder K, Berry G, et al. Bcl-2 and Bax interactions in mitochondria probed with green fluorescent protein and fluorescence resonance energy transfer. Nat Biotechnol, 1998, 16: 547-552

36 Guo B, Zhai D, Cabezas E, et al. Humanin peptide suppresses apoptosis by interfering with Bax activation. Nature, 2003, 423: 456-461

37 Rosse T, Olivier R, Monney L, et al. Bcl-2 prolongs cell survival after Bax-induced release of cytochrome c. Nature, 1998, 391: 496-499

Open Access This article is distributed under the terms of the Creative Commons Attribution License which permits any use, distribution, and reproduction in any medium, provided the original author(s) and source are credited. 